\title{
¿Podemos Convertir el Aerosol Dental en Antiséptico y Viricida?.
}

\section{Can We Convert Dental Spray in Antiseptic and Virucidal?.}

\author{
1. Mora Pavic Odontología Santiago Chile. \\ Licenciado en Odontología, Especialista en \\ Periodoncia, Mg. en Psicología Organizacional
}

${ }^{*}$ Correspondencia a: Dr. Marco Mora Reyes | Dirección: Apoquindo 5123, Las Condes, Santiago -Chile | E-mail: marco.mora@morapavic.cl Trabajo recibido 07/10/2021

Aprobado para su publicación 11/10/2021

\author{
Marco Mora Reyes ${ }^{*}$
}

\section{Señor Editor:}

Todo el año 2020, la odontología fue profundamente afectada por la pandemia de COVID-19(1), el 15 de marzo del 2020 el New York Time realiza un reportaje titulado: "The Workers Who Face the Greatest Coronavirus Risk", situando a los dentistas como uno de los profesionales de mayor riesgo de contagiarse y transmitir el SARS-CoV2 ${ }^{(2)}$.

Desde el 18 de marzo de 2020 la Asociación Dental Americana (ADA) y OMS recomiendan que los dentistas de todo Estados Unidos pospongan los procedimientos electivos en respuesta a la propagación de COVID-19. A este llamado se unieron diversas asociaciones gremiales y sociedades científicas de múltiples países, incluyendo Chile, recomendando esta suspensión voluntaria. Por ello, esta pandemia ha generado serias implicaciones económicas en las prácticas dentales en todo el mundo ${ }^{(3)}$, como también la formación universitaria y las políticas públicas para la salud oral de la población. Tanto ADA como el CDC (Centros para el Control y la Prevención de Enfermedades de EEUU) recomendaron minimizar todos los aerosoles y salpicaduras contaminados con sangre ${ }^{(4)}$. El virus SARS-CoV-2 ha mostrado permanecer viable en aerosoles por horas, lo que apoyaría la transmisión por esta vía. Esto resuena con la idea de que esta transmisión puede darse por vía nosocomial, como en el caso de otros coronavirus ${ }^{(5)}$.

No obstante desde el 2004 Harrel y Col(6) ya decían que la propagación aérea del sarampión, la tuberculosis y el SARS está bien documentada en la literatura médica y que estos aerosoles representan una ruta potencial para la transmisión de enfermedades. La literatura también documenta que la contaminación en el aire se puede minimizar de manera fácil y económica colocando varios pasos de control de infección en las precauciones de rutina utilizadas durante todos los procedimientos dentales ${ }^{(6)}$. Sin embargo, con todo estos llamados y dudas sobre el COVID, el uso de Aerosoles en Odontología se convirtió en el enemigo número uno de los equipos de salud oral como de los pacientes odontológicos.

En este contexto, un grupo multidisciplinarios de nuestra clínica, revisó la evidencia disponible para responderse la pregunta: ¿Podemos Convertir el Aerosol Dental en Antiséptico y Viricida?. Con el fin de realizar un aporte a la odontología nacional y mundial y hacer que la atención dental sea más segura y confiable en tiempos de pandemia y los paciente no postergaran sus tratamientos dentales. Las características con las que debería contar el nuevo aerosol deberían ser las siguientes: 1)Poseer un efecto viricida reconocido y/o homologado para SARS-CoV-2, de acuerdo con la evidencia científica y el marco regulatorio(7, 8), 2) Actuar como un antiséptico bucal validado y probado(9, 10). 3) Servir como sanitizante ambiental ${ }^{(11)}$ y 4) Tener el potencial de ser incorporado a Unidades de tratamiento dental|(12).

Es así como entregamos una formulación de Agua Electrolizada, la que se ha utilizado hace más de 30 años en diferentes tipos de industrias como potente biocida, con resultados exitosos, sin efectos colaterales adversos e innocuo para la salud humana, animal y medioambiental ${ }^{(10,13)}$. Su capacidad bactericida y viricida (particularmente contra SARSCoV-2), radica básicamente en un alto nivel de ORP, combinado con bajas concentración de ácido hipocloroso.

La utilización de Agua Electrolizada en la turbina dental sería una herramienta innovadora en el escenario de pandemia actual. Su uso efectivo ha sido demostrado en la prevención de enfermedades nosocomiales derivadas de la atención dental.

De esta manera, en mayo del 2020 lanzamos una innovación disruptiva en medios masivos de comunicación y redes sociales ${ }^{(15,16)}$, bajo el contexto de emergencia sanitaria de esta pandemia, con el fin de entregar el mensaje a la comunidad que la atención odontológica era segura y necesaria. Como así lo ratificaría posteriormente la propia ADA en agosto del 2020, emitiendo un comunicado en el que declaraba estar "respetuosamente en total desacuerdo, con la recomendación de la OMS de retrasar la atención dental rutinaria debido a la pandemia", detallando su presidente que: "La salud bucal es parte integral de la salud en general y la odontología es un cuidado de la salud esencial debido a su papel en la evaluación, el diagnóstico, la prevención o el tratamiento de enfermedades bucodentales que pueden afectar la salud sistémica"(14).

Es así como el 4 de noviembre del 2020, la innovación de nuestra Agua Electrolizada se le otorga el registro como enjuagatorio bucal sin flúor por parte del Instituto de Salud Pública de Chile bajo el número ISP: N²398C-39/20. Desde la aprobación de este registro del ISP, nos pusimos en contacto con la Unidad Virología Aplicada de Escuela de Medicina de la Pontificia Universidad Católica de Chile, con la evidencia científica que disponíamos para Agua Electrolizada en su actividad viricida para SARS-CoV2, con el fin de realizar las 
pruebas para nuestra propia formulación aprobada por el ISP.

En el reciente informe del 6 de octubre del 2021, sobre la "Evaluación de la Actividad Microbicida contra Virus en Suspensión", los resultados permitieron concluir que nuestra Solución Bucal número ISP: $\mathrm{N}^{\circ} 2398 \mathrm{C}-39 / 20$ posee actividad viricida contra virus infeccioso SARSCoV-2, cuando se emite desde una turbina dental. Generando una reducción de 4 logaritmos, lo que equivale a reducir en un 99,99\% de virus infeccioso de SARS-CoV-2 en 20 segundos.

Gracias a esta investigación y desarrollo, desde mayo del 2020, en nuestra clínica, pudimos modificar la recomendación de esperar ventilar el box dental 20 a 30 minutos entre atenciones que implicaran uso de aerosol dental, por la espera normal que permita limpiar y desinfectar entre paciente y paciente. Nos permitieron dar más número de atenciones y que estas fuesen más seguras en pandemia, basados en la revisión de la evidencia científica, al respondernos positivamente nuestra pregunta: ¿Podemos Convertir el Aerosol Dental en Antiséptico y Viricida?.

Hoy nos asiste el deber de comunicar nuestra revisión bibliográfica sobre el agua electrolizada y su uso en el aerosol dental en revista indexadas, como también debemos publicar los diferentes validaciones de laboratorios que hemos realizados con este enjuague bucal efectivo en inactivar SARS-CoV2 en 99,99\%, pudiendo convertir a la odontología en el centro del control de los contagios de este virus respiratorios, al bajar tan eficazmente la carga viral con enjuagues bucales innocuos. Además reforzando que los dentistas desde siempre hemos manejado de forma segura los virus y bacterias a 30 centímetros de la boca de nuestros pacientes y debemos ser un gran aporte para el resto de la medicina y salud pública.

\section{Bibliografía}

1. Centro de Epidemiología y Vigilancia de las Enfermedades Orales (CEVEO). La Odontología en los tiempos del coronavirus-COVID-19. Int J Interdiscip Dent. 2020;13(1):2. DOI: http://dx.doi.org/10.4067/S2452-55882020000100002.

2. Gamio L. The Workers Who Face the Greatest Coronavirus Risk. [Consultado 30/03/2020]. Disponible en: https://www.nytimes.com/interactive/2020/03/15/business/economy/coronavirus-worker-risk.html

3. Farooq I \& Ali S. COVID-19 outbreak and its monetary implications for dental practices, hospitals and healthcare workers. Postgrad Med J. 2020;96:791-2.

4. CDC. Healthcare Workers. Centers for Disease Control and Prevention. [Consultado 12/12/2020]. Disponible en: https://www.cdc.gov/coronavirus/2019-ncov/hcp/ dental-settings.html (2020).

5. Tang S. et al. Aerosol transmission of SARS-CoV-2? Evidence, prevention and control. Environ Int. 2020;144:106039.

6. Harrel SK \& Molinari J. Aerosols and splatter in dentistry: a brief review of the literature and infection control implications. J Am Dent Assoc. 2004;135:429-37.

7. List N: Productos con rol antiviral emergente qué actúan contra el coronavirus SARS-CoV-2. Información recopilada desde (EPA, 2021). [Consultado 06/10/2021] https://espanol.epa.gov/sites/default/files/2020-05/documents/052120_spanish_ x0483_spanish_list_n.pdf?Versionld=B.JmtNJuRvXYeEqfyDBuuJ1yQIS7MpOV

8. Tamaki S, Bui VN, Ngo LH, Ogawa H \& Imai K. Virucidal effect of acidic electrolyzed water and neutral electrolyzed water on avian influenza viruses. Arch Virol. 2014;159:405-12.

9. Escobar DFG, Ramírez DMB, Pérez DAT, Robles JC \& Villamil GIL. Efecto de enjuagues de ácido hipocloroso sobre el $\mathrm{pH}$ de la saliva: estudio in vitro / Effect of
Hypochlorous Acid as a Mouthwash on Salivary pH: in vitro Study. Univ Odontol. 2015;34:83-90.

10. Block MS \& Rowan BG. Hypochlorous Acid: A Review. J Oral Maxillofac Surg. 78;2020:1461-6.

11. Chuang $\mathrm{CY}$, Yang S, Huang $\mathrm{HC}$, Luo $\mathrm{CH}$, Fang W, Hung PC, \& Chung PR. Applying the membrane-less electrolyzed water spraying for inactivating bioaerosols. Aerosol Air Qual Res. 2013;13(1):350-9.

12. Martin, M. V. \& Gallagher, M. A. An investigation of the efficacy of super-oxidised (Optident/Sterilox) water for the disinfection of dental unit water lines. Br Dent J. 2005;198:353-4; discussion 347.

13. Morita C, Nishida T \& Ito K. Biological toxicity of acid electrolyzed functional water: effect of oral administration on mouse digestive tract and changes in body weight. Arch Oral Biol. 2011;56:359-66.

14. ADA. ADA releases interim guidance on minimizing COVID-19 transmission risk when treating dental emergencies. 2020. [Consultado 01/09/2020]. Disponible en: https://la.dental-tribune.com/news/ada-vs-oms-la-odontologia-es-atencion-de-lasalud-esencial/

15. ¡BUENAS NOTICIAS! Podremos combatir Coronavirus convirtiendo el aerosol dental en viricida. Canal Dr. Federico Baena. [Consultado 06/10/2021]. Disponible en:www.youtube.com/watch?v=88gX0eg7Vm8\&t=194s

16. Innovación con sentido - Spray dental antiséptico y viricida en tratamientos odontológicos. Programa Conectados TVChile - TVN. [Consultado 06/10/2021]

Disponible en: https://www.youtube.com/watch?v=9s07ZZ1Apn8 